\title{
Angiogenesis for tumor vascular normalization of Endostar on hepatoma 22 tumor-bearing mice is involved in the immune response
}

\author{
QINGYU XU ${ }^{1 *}, J_{U N F E I ~ G U}^{2 *}$, YOU LV ${ }^{1}$, JIARUI YUAN ${ }^{2}$, NAN YANG $^{2}$, JUAN CHEN $^{2}$, \\ CHUNFEI WANG ${ }^{2}$, XUEFENG HOU $^{2}$, XIAOBIN JIA $^{3}$, LIANG FENG ${ }^{3}$ and GUOWEN YIN ${ }^{1}$ \\ ${ }^{1}$ Department of Intervention, Cancer Hospital of Jiangsu, Nanjing, Jiangsu 210009; ${ }^{2}$ College of Pharmacy, \\ Nanjing University of Chinese Medicine, Nanjing, Jiangsu 210023; ${ }^{3}$ Key Laboratory of Delivery Systems \\ of Chinese Materia Medica, Jiangsu Provincial Academy of Chinese Medicine, Nanjing, Jiangsu 210028, P.R. China
}

Received December 6, 2015; Accepted May 18, 2017

DOI: $10.3892 / \mathrm{ol} .2018 .7734$

\begin{abstract}
Tumor vascular normalization involved in immune response is beneficial to the chemotherapy of tumors. Recombinant human endostatin (Endostar), an angiogenesis inhibitor, has been demonstrated to be effective in hepatocellular cancer (HCC). However, its vascular normalization in $\mathrm{HCC}$ and the role of the immune response in angiogenesis were unclear. In the present study, effects of Endostar on tumor vascular normalization were evaluated in hepatoma 22 (H22) tumor-bearing mice. Endostar was able to inhibit the proliferation and infiltration of tumor cells and improve $\alpha$-fetoprotein, tumor necrosis factor- $\alpha$ and cyclic adenosine 5'-phosphate levels in the serum of H22-bearing mice, as well as the protein expression levels of the immune factors interferon- $\gamma$ and cluster of differentiation (CD)86 in liver tissue. Endostar also exhibited more marked downregulation of the levels of vascular endothelial growth factor, CD31, matrix metalloproteinase (MMP)-2, MMP-9 and interleukin-17 during day 3-9 treatment, resulting in short-term normalization of
\end{abstract}

Correspondence to: Dr Guowen Yin, Department of Intervention, Cancer Hospital of Jiangsu, 42 Hundred Children Pavilion, Nanjing, Jiangsu 210009, P.R. China

E-mail: xqy1984king@163.com

Dr Liang Feng, Key Laboratory of Delivery Systems of Chinese Materia Medica, Jiangsu Provincial Academy of Chinese Medicine, 100 Shi Zi Street, Nanjing, Jiangsu 210028, P.R. China

E-mail:wenmoxiushi@163.com

*Contributed equally

Abbreviations: HCC, hepatocellular cancer; TAF, tumor angiogenesis factor; VEGF, vascular endothelial growth factor; FBS, fetal bovine serum; H\&E, hematoxylin and eosin; LPA, lysophosphatidic acid; MMP, matrix metalloproteinases

Key words: hepatocellular cancer, Endostar, vascular normalization, immune response tumor blood vessels. The period of vascular normalization was 3-9 days. The results of the present study demonstrated that Endostar was able to induce the period of vascular normalization, contributing to a more efficacious means of HCC treatment combined with other chemotherapy, and this effect was associated with the immune response. It may be concluded that Endostar inhibited immunity-associated angiogenesis behaviors of vascular endothelial cells in response to HCC. The results of the present study provided more reasonable possibility for the combination therapy of Endostar for the treatment of HCC.

\section{Introduction}

Hepatocellular cancer (HCC) has been regarded as one of the most common malignancies responsible for cancer-associated mortality (1). Conventionally, radiotherapy and chemotherapy have been used in clinical practice for the treatment of $\mathrm{HCC}(2)$. Of note, these conventional therapies are not ideal due to the toxic side effects and easily induced tumor resistance (3). A previous study demonstrated that the tumorigenesis and deterioration of HCC depends on tumor cell proliferation, and is also associated with tumor angiogenesis (4). Thus, the treatment of blocking the supply for tumor blood to kill tumor cells was gradually recognized. Folkman (5) proposed a hypothesis that tumor growth relies on blood supply. It has been considered that cancer does not depend on blood supply in the early period, but when the diameter of tumor grows $>1 \mathrm{~mm}^{3}$ with the secretion of a variety of tumor angiogenesis factors (TAFs) (6). TAFs induce the proliferation and migration of endothelial cells, and generate new capillaries to ensure continued tumor growth and metastasis $(7,8)$. Inhibition of tumor angiogenesis may be a useful therapeutic approach (9).

Recombinant human endostatin (Endostar), expressed and purified in Escherichia coli with an additional 9-amino-acid sequence and forming another his tag structure, was developed and approved by the State Food and Drug Administration of China in 2005 (10). It has been shown to promote the efficiency of chemotherapy in the treatment of advanced non-small cell lung cancer Phase I clinical trials, and also to be effective 
in HCC $(11,12)$. Endostar is able to selectively inhibit the proliferation, migration, adhesion and survival of endothelial cells (13). Studies have demonstrated that Rh-endostatin is able to transiently normalize tumor vasculature and promote chemotherapy drugs permeating into the tumor during the normalization window with synergistic efficacy $(14,15)$.

The growth and progression of HCC may be achieved by enhancing tumor angiogenesis and tumor cell proliferation, and by creating an immunosuppressed microenvironment (16). It is well documented that tumor angiogenesis is induced by an activation of complement mediators, which favor an immunosuppressive microenvironment and also activate inflammation (17-19). Cellular immunity such as an interaction of cytotoxic T-lymphocyte-associated protein 4 immunoglobulin (CTLA4-Ig)/cluster of differentiation (CD)86 on interferon- $\gamma($ IFN- $\gamma$ ) and interleukin-17 (IL-17) involved in the tumor anti-angiogenesis stimulate the proliferation and migration of naturally quiescent endothelial cells, resulting in the expression of vascular endothelial growth factor (VEGF) receptor-2 (VEGFR-2), which are relevant for inflammatory and angiogenetic processes (20). Anti-angiogenic substances such as VEGF and VEGFR inhibitors, including endostatin, angiostatin, atrasentan and matrix metalloproteinase (MMP) inhibitors, inhibit endothelial cell proliferation and the formation of tumor angiogenesis $(21,22)$. However, the effect of Endostar on vascular normalization in hepatoma 22 (H22) tumor-bearing mice and the role of immune response in angiogenesis were unclear.

The aim of the present study was to evaluate the vascular normalization in $\mathrm{H} 22$ tumor-bearing mice, and to investigate the role of the immune response in angiogenesis, providing experimental evidence for clinical application.

\section{Materials and methods}

Chemicals and reagents. Endostar was provided by Simcere Pharmaceutical Group (Nanjing, China). RPMI-1640 medium and trypsin were provided by Nanjing KeyGen Biotech Co., Ltd. (Nanjing, China). Fetal bovine serum (FBS) was purchased from Gibco (Thermo Fisher Scientific, Inc., Waltham, MA, USA). Antibodies against CD31 (cat. no. ab28364), hypoxia-inducible factor-1 $\alpha$ (HIF-1 $\alpha$; cat. no. ab2185), MMP-2 (cat. no. ab37150), MMP-9 (cat. no. ab38898), VEGF (cat. no. ab46154), IFN- $\gamma$ (cat. no. ab198801), IL-17 (cat. no. ab79056) and CD86 (cat. no. ab119857) were provided by Abcam (Cambridge, MA, USA). Mouse ELISA kits for tumor necrosis factor- $\alpha$ (TNF- $\alpha$; MK1169), IFN- $\gamma$ (MK1205), IL-17 (MK1445), $\alpha$-fetoprotein (AFP; MK2689) and cyclic adenosine 5'-phosphate (cAMP; MK2893) were ordered from Wuhan Boster Biological Technology, Ltd. (Wuhan, China). A monoclonal $\beta$-actin antibody (sc-47778) was bought from Santa Cruz Biotechnology, Inc. (Dallas, TX, USA). The secondary antibody (horseradish peroxidase conjugated-anti-rabbit $\mathrm{IgG}$ ) was obtained from Invitrogen (A-11034; Thermo Fisher Scientific, Inc.).

Cell culture. The mouse H22 cell line was purchased from the Tumor Institute of the Chinese Academy of Medical Sciences (Shanghai, China). H22 cells were incubated in RPMI-1640 medium containing $10 \% \mathrm{FBS}, 80 \mathrm{U} / \mathrm{ml}$ penicillin and $0.08 \mathrm{mg} / \mathrm{ml}$ streptomycin. Cells were cultured in an incubator at $5 \% \mathrm{CO}_{2}$ and $37^{\circ} \mathrm{C}$. The medium was renewed every other day. These cells were detached by $0.25 \%$ trypsin containing $0.01 \%$ EDTA and used for seeding. Cells passaged between three and four times were used for subsequent experiments.

H22-bearing C57BL/6 mice and treatment. A total of 86 male C57B L/6 (C57 black 6) mice at 6-8 weeks (18-22 g) were purchased from the Shanghai Laboratory Animal Center (Shanghai, China). All mice were maintained at the clean standard of laboratory animals. Mice were housed for 7 days to adapt to the environment and maintained at a temperature of $25^{\circ} \mathrm{C}$ with a relative humidity of $45 \%$. Animals were housed in the Experimental Animal Center of Jiangsu Province (Nanjing, China) on a 12/12 h light/dark cycle with food and water ad libitum. The animal experiment protocol was reviewed and approved by the Institutional Animal Care and Use Committee of the Jiangsu Provincial Academy of Chinese Medicine (Jiangsu, China). Cell suspension containing $\mathrm{H} 22$ cells $\left(1 \times 10^{6}\right.$ cells $\left./ \mathrm{ml} ; 0.2 \mathrm{ml}\right)$ was injected into liver tissues of C57BL/6 mice. The mice with H22 cells were then randomly divided into two groups, with 40 mice in each group, and administered for 12 consecutive days. The other 6 mice were set as a blank control. The Endostar group was administered Endostar every day at the dose of $0.5 \mathrm{mg} / \mathrm{kg}$. Mice in the model group and blank control group were treated with normal saline at the same amount as Endostar. The model group mice and Endostar-treated mice were sacrificed at days 1, 3, 6, 9 and 12, and HCC tissues were removed immediately.

Hematoxylin and eosin $(H \& E)$ staining. HCC tissues were fixed in $4 \%(\mathrm{w} / \mathrm{v})$ paraformaldehyde at room temperature for $24 \mathrm{~h}$. A microscope slide was used to bear cryosections or rehydrated hepar tissue sections ( $4 \mu \mathrm{m}$ thick). The sections were dewaxed in xylene and rehydrated through decreasing concentrations of ethanol. The slide was immersed in $0.3 \% \mathrm{H}_{2} \mathrm{O}_{2}$ for $30 \mathrm{sec}$ with agitation by hand. The slide was then dipped into a Coplin jar containing Mayer's hematoxylin and agitated for $30 \mathrm{sec}$ at $50^{\circ} \mathrm{C}$. The slide was rinsed in water for $1 \mathrm{~min}$ and stained with $1 \%$ eosin $\mathrm{Y}$ solution for between 10 and $30 \mathrm{sec}$ at $30^{\circ} \mathrm{C}$ with agitation. Next, two changes of $95 \%$ alcohol and two changes of $100 \%$ alcohol for $30 \mathrm{sec}$ each were used to dehydrate the sections. The alcohol was extracted by washing twice with xylene. Drops of neutral gum (Bioworld Technology, Inc., St. Louis Park, MN, USA) were then added and covered with a coverslip. Liver tissues were stained with $H \& E$ and images were captured using a digital camera.

ELISA for immunological and tumor-associated factors. ELISA was used to determine the levels of AFP, cAMP, TNF- $\alpha$, IFN- $\gamma$ and IL-17 in serum or HCC tissues of H22-bearing C57BL/6 mice. Blood was obtained from mice retinal veins under sterile conditions and then centrifuged at $1,000 \mathrm{x} \mathrm{g}$ for $10 \mathrm{~min}$ at $4^{\circ} \mathrm{C}$. HCC tissues were lysed by adding $400 \mu \mathrm{llysis}$ buffer containing $20 \mathrm{mM}$ sodium phosphate buffer, $\mathrm{pH} 7.4$, $1 \%$ Triton $\mathrm{X}-100,150 \mathrm{mM} \mathrm{NaCl}$ and $5 \mathrm{mM}$ EDTA (23). The lysate was left on ice for $30 \mathrm{~min}$, vortex-mixed and centrifuged at $14,000 \mathrm{x} \mathrm{g}$ at $4^{\circ} \mathrm{C}$ for $15 \mathrm{~min}$. The supernatant was collected for subsequent use. ELISA was performed according 
to the manufacturer's protocols. At the end of the reaction, the optical density value of samples was read at $450 \mathrm{~nm}$ using a microplate reader (SPECTRAmax 19.0; Molecular Devices, LCC, Sunnyvale, CA, USA).

Western blotting. Western blotting was used to determine the protein expression of CD31, HIF-1 $\alpha$, MMP-2, MMP-9, VEGF, TNF- $\alpha$, IFN- $\gamma$, IL-17 and CD86. Following treatment with Endostar, HCC tissues of the model group mice and Endostar-treated mice were washed with saline. Subsequently, these tissues were lysed with ice-cold radioimmunoprecipitation assay buffer containing $50 \mathrm{mM}$ Tris, $1 \%$ Nonidet P-40 and $2 \mathrm{mM}$ EDTA, $11.5 \mu \mathrm{g} / \mathrm{ml}$ aprotinin, $120 \mathrm{mM} \mathrm{NaCl}, 11.5 \mu \mathrm{g} / \mathrm{ml}$ leupeptin, $100 \mathrm{mM}$ sodium fluoride, $50 \mu \mathrm{g} / \mathrm{ml}$ phenylmethylsulfonyl fluoride and $0.2 \mathrm{mM}$ sodium orthovanadate for $30 \mathrm{~min}$ at $4^{\circ} \mathrm{C}$. The concentration of protein was quantified using the bicinchoninic acid method (Pierce; Thermo Fisher Scientific, Inc.) according to the manufacturer's protocol. Subsequently, the same amount of protein $(50 \mu \mathrm{g})$ from each sample was resolved by $12 \%$ SDS-PAGE and transferred to polyvinylidene fluoride membranes. Membranes were blocked with 5\% bovine serum albumin (BSA; Sigma-Aldrich; Merck $\mathrm{KGaA}$, Darmstadt, Germany) for $2 \mathrm{~h}$ at room temperature, washed three times in TBS-Tween-20, and incubated with primary antibodies against CD31 (dilution, 1:1,000), HIF-1 $\alpha$ (dilution, 1:500), MMP-2 (dilution, 1:500), MMP-9 (dilution, 1:500), VEGF (dilution, 1:500), TNF- $\alpha$ (dilution, 1:1,000), IFN- $\gamma$ (dilution, 1:1,000), IL-17 (dilution, 1:1,000), CD86 (dilution, $1: 1,000$ ) and $\beta$-actin (dilution, 1:500) overnight at $4^{\circ} \mathrm{C}$. Subsequently, membranes were incubated with the previously described secondary antibody (dilution, 1:5,000) for $1 \mathrm{~h}$ at room temperature. Finally, the protein bands were treated with enhanced chemiluminescent reagents (Pierce; Thermo Fisher Scientific, Inc.) for visualization. $\beta$-actin was used as a loading control.

Reverse transcription-quantitative polymerase chain reaction (RT-qPCR) analysis. RT-qPCR was used to determine the mRNA expression of HIF-1 $\alpha$ and VEGF. Total RNA of hepar samples was extracted using TRIzol reagent (Invitrogen; Thermo Fisher Scientific, Inc.). It was then reverse-transcribed with a SuperScript III First-Strand Synthesis System for RT-qPCR following the manufacturer's protocol. The primers were as follows: HIF-1 $\alpha$ forward, 5'-AAACCTAAATGTTCT GCCTAC-3' and reverse, 5'-GGATGTTAATAGCGACAA AGT-3'; VEGF forward, 5'-AGGGAAGAGGAGGAGATG AGA-3' and reverse, 5'-GGCTGGGTTTGTCGGTGTT-3'; GAPDH forward, 5'-ATGACATCAAGAAGGTGGTG-3' and reverse, 5'-CATACCAGGAAATGAGCTTG-3'. Primers were selected and constructed using Primer Premier 5 (PREMIER Biosoft, Palo Alto, CA, USA). qPCR was performed with an ABI 7900 sequence detector (Thermo Fisher Scientific, Inc.) using the SYBR Green method and $\mathrm{d}(\mathrm{N})_{6}$ random hexamers. PCR thermocycling parameters were $95^{\circ} \mathrm{C}$ for $10 \mathrm{~min}$, and 40 cycles of $95^{\circ} \mathrm{C}$ for $15 \mathrm{sec}$ and $60^{\circ} \mathrm{C}$ for $1 \mathrm{~min}$. GAPDH was used as an internal competitive reference standard; the comparative $\mathrm{Cq}$ (quantitative cycle) method was used to calculate the relative changes in gene expression using the $2^{-\Delta \Delta \mathrm{Cq}}$ method (24). Each sample was run in triplicate, each experiment was repeated three times.
Immunohistochemistry. The detailed operational procedure was performed as described previously (25). Briefly, mice were anesthetized with ether for $60 \mathrm{sec}$ and then sacrificed by cervical dislocation. The tumor-bearing liver tissues were taken for fixing with $4 \%$ freshly prepared paraformaldehyde at room temperature in $0.1 \mathrm{M}$ PBS ( $\mathrm{pH} 7.2$ ) for $24 \mathrm{~h}$. The liver tissues were dehydrated by serial gradient concentrations of alcohol and then embedded in paraffin blocks. Sections of $4 \mu \mathrm{m}$ thickness were cut and mounted on specific slides for immunohistochemistry. Following deparaffinization and dehydration with a graded series of alcohol $(100,95,80$ and $70 \%$ for 2 min each) $3 \%$ hydrogen peroxide was used to block endogenous peroxidase for $20 \mathrm{~min}$ at room temperature. Following washing with PBS (pH 7.2), the sections were treated with 5\% BSA (Sigma-Aldrich; Merck KGaA) for $30 \mathrm{~min}$ at $37^{\circ} \mathrm{C}$ to prevent non-specific reactions. Sequentially, these sections were incubated with the primary antibodies, including anti-IL-17 (dilution, 1:500), anti-CD86 (dilution, 1:500) and anti-IFN- $\gamma$ (dilution, 1:500) at $4^{\circ} \mathrm{C}$ overnight. Sections were washed with PBS three times, and then incubated with the previously described secondary antibody (dilution, 1:1,000) at $37^{\circ} \mathrm{C}$ for $2 \mathrm{~h}$. Finally, sections were stained with 3,3'-diaminobenzidine for $1 \mathrm{~min}$ at room temperature. The sections were visualized and images were captured under light microscopy at x200 magnification (IX71) using an Olympus image capturing system (Olympus Corporation, Tokyo, Japan), and the images were then analyzed and quantified using Image-Pro Plus software 6.0 (Media Cybernetics, Inc., Rockville, MD, USA). PBS was used as primary antibody for normalization to the loading control.

Statistical analysis. Data are expressed as the mean \pm standard deviation. Statistical analysis was performed by one-way analysis of variance based on Student's two-tailed unpaired t-test or Dunnett's multiple comparisons test using SPSS software (version 16.0; SPSS, Inc., Chicago, IL, USA). Image-Pro Plus software (version 6.0; Media Cybernetics, Inc.) was used for processing images. $\mathrm{P}<0.05$ was considered to indicate a statistically significant difference.

\section{Results}

Pathological observation of liver tissue. Following treatment for 5 days, H\&E staining of liver tissues was performed to observe liver histological morphology injury. As presented in Fig. 1A, H\&E staining revealed that liver tissues of H22 cell-injected mice (HCC mice) possessed typical basic characteristics of tumor cells, with larger volumes and irregular shaped nuclei compared with mice in the blank control group (Fig. 1B). Following treatment with Endostar (0.5 mg/kg/day), the proliferation and infiltration of tumor cells was inhibited (Fig. 1C).

Effects of Endostar on the levels of AFP and cAMP in H22-bearing mice. As shown in Table I, the level of serum AFP produced by the majority of HCCs was significantly increased in HCC mice when compared with blank controls $(28.19 \pm 3.26 \mathrm{ng} / \mathrm{ml})(\mathrm{P}<0.05)$. A positive association was observed between AFP level and treatment time; the level of AFP gradually increased with the extension of time from 
Table I. Effect of Endostar on the levels of AFP, TNF- $\alpha$ and cAMP in hepatoma 22-bearing mice $(n=6)$.

\begin{tabular}{|c|c|c|c|c|c|c|c|c|c|}
\hline \multirow[b]{2}{*}{ Day } & \multicolumn{3}{|c|}{ AFP, ng/ml } & \multicolumn{3}{|c|}{$\mathrm{TNF}-\alpha, \mathrm{pg} / \mathrm{mg}$} & \multicolumn{3}{|c|}{$\mathrm{cAMP}, \mathrm{nmol} / \mathrm{ml}$} \\
\hline & Blank & Model & Endostar & Blank & Model & Endostar & Blank & Model & Endostar \\
\hline 1 & $28.19 \pm 3.26$ & $29.21 \pm 9.01$ & $29.13 \pm 4.56$ & $0.41 \pm 0.04$ & $0.95 \pm 0.12$ & $0.63 \pm 0.14$ & $0.63 \pm 0.17$ & $0.51 \pm 0.07$ & $0.52 \pm 0.12$ \\
\hline 3 & & $32.91 \pm 3.98^{a}$ & $30.17 \pm 6.11$ & & $3.51 \pm 0.91^{\mathrm{a}}$ & $2.11 \pm 0.61^{\mathrm{c}}$ & & $0.45 \pm 0.08^{\mathrm{a}}$ & $0.51 \pm 0.09$ \\
\hline 6 & & $36.42 \pm 4.66^{\mathrm{a}}$ & $31.62 \pm 5.87^{c}$ & & $5.36 \pm 0.74^{\mathrm{b}}$ & $2.45 \pm 0.85^{\mathrm{d}}$ & & $0.42 \pm 0.09^{\mathrm{b}}$ & $0.49 \pm 0.12^{c}$ \\
\hline 9 & & $42.95 \pm 8.01^{\mathrm{b}}$ & $35.21 \pm 4.03^{\mathrm{d}}$ & & $7.18 \pm 0.71^{\mathrm{b}}$ & $3.27 \pm 0.97^{\mathrm{d}}$ & & $0.09 \pm 0.08^{\mathrm{b}}$ & $0.39 \pm 0.09^{\mathrm{c}}$ \\
\hline 12 & & $56.26 \pm 3.98^{\mathrm{b}}$ & $49.82 \pm 4.65^{\mathrm{e}}$ & & $7.31 \pm 0.13^{b}$ & $7.08 \pm 1.01^{\mathrm{e}}$ & & $0.07 \pm 0.01^{\mathrm{b}}$ & $0.16 \pm 0.03^{\circ}$ \\
\hline
\end{tabular}

All experiments were performed at least three times. ${ }^{\mathrm{a}} \mathrm{P}<0.05,{ }^{\mathrm{b}} \mathrm{P}<0.01$, model vs. blank control; ${ }^{\mathrm{c}} \mathrm{P}<0.05$, ${ }^{\mathrm{d}} \mathrm{P}<0.01$, Endostar treatment vs. the model group at the same day; ${ }^{\mathrm{P}}<0.01$, the level at day 12 vs. the level at day 9 in the Endostar group. AFP, $\alpha$-fetoprotein; TNF- $\alpha$, tumor necrosis factor- $\alpha$; cAMP, cyclic adenosine 5'-phosphate.

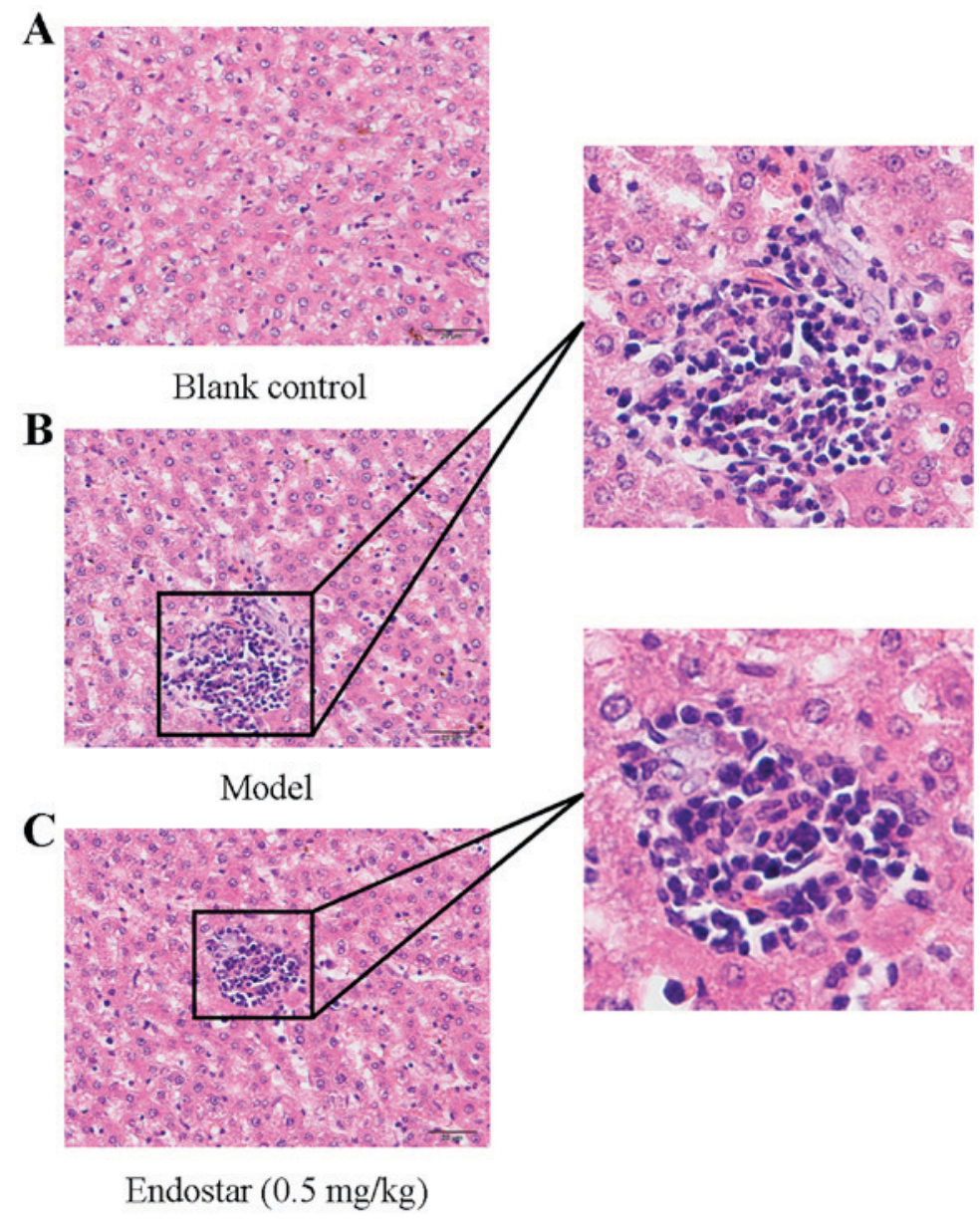

Figure 1. Pathological observation of liver tissue in different groups (hematoxylin and eosin staining; magnification, x400). (A) blank control group; (B) model group; (C) Endostar-treated group.

day 3 to 9. Although no significant difference was observed in the AFP level between the Endostar-treated group and the model group on day 12, serum AFP levels were decreased significantly by the treatment of Endostar from days 3 to 9 , compared with the model mice $(\mathrm{P}<0.05)$.

cAMP has previously been associated with HCC (26). The serum cAMP level was markedly decreased in H22-bearing mice from a peak on day 1 of $0.51 \pm 0.07 \mathrm{nmol} / \mathrm{ml}$ to a low of $0.07 \pm 0.01 \mathrm{nmol} / \mathrm{ml}$ on day $12(\mathrm{P}<0.05)$. Endostar treatment resulted in a significant increase in the cAMP level compared with the model group at the same day until day 12 (Table I). Therefore, it was hypothesized that Endostar may improve the levels of AFP and cAMP in H22-bearing mice following administration at days 3 to 9 , meaning that the effective work time continued for 6 days.

Effects of Endostar on angiogenesis-associated proteins in liver tissues at different treatment times. In order to screen 

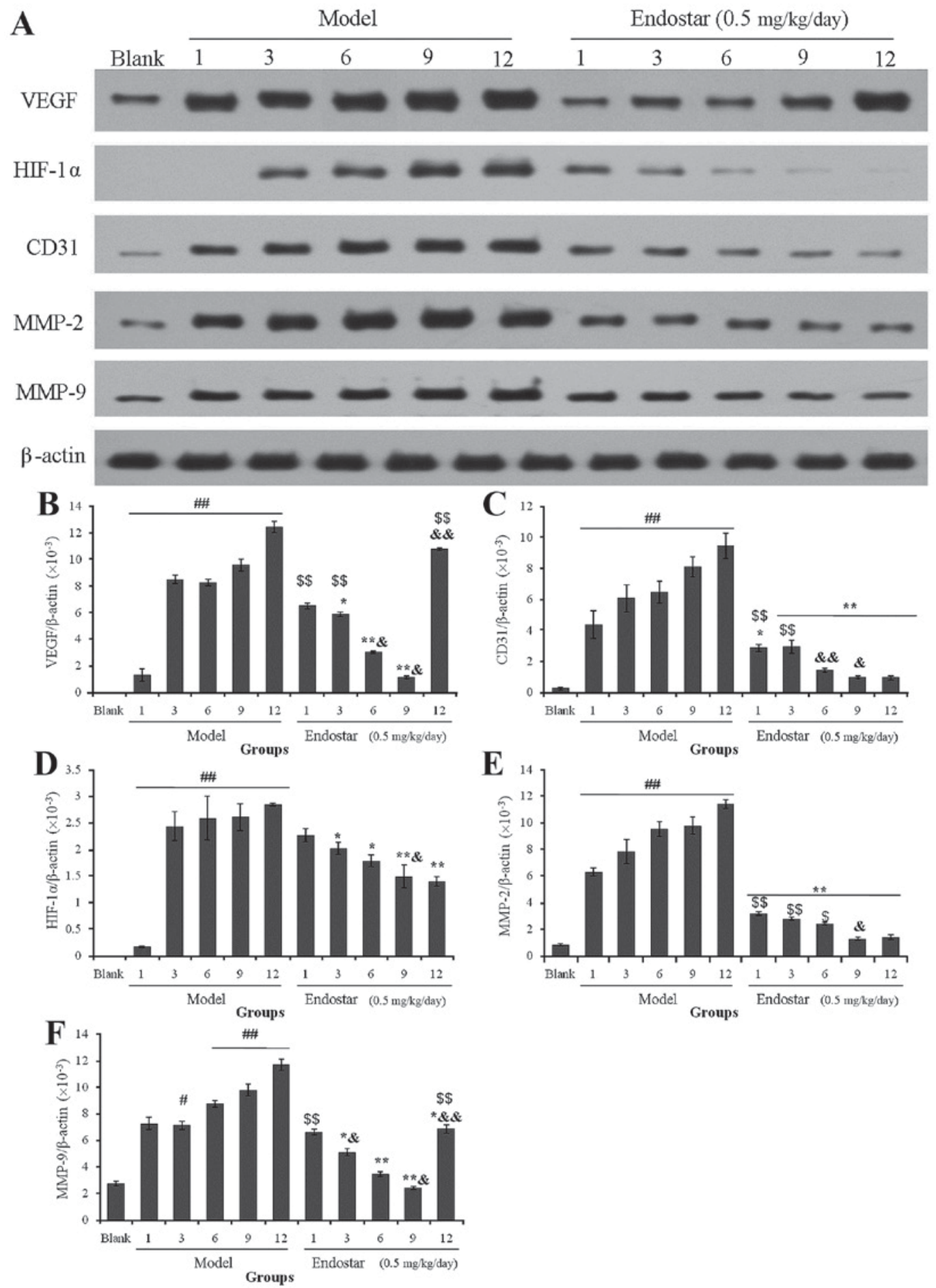

Figure 2. (A) Effects of Endostar on the expression of angiogenesis-associated proteins in mouse liver tissues during treatment. Protein from liver tissues was extracted and protein expression of (B) VEGF, (C) CD31, (D) HIF-1 $\alpha$, (E) MMP-2 and (F) MMP-9 was analyzed using Image-Pro Plus 6.0. All experiments were performed at least three times. Results are presented as the mean \pm standard deviation $(\mathrm{n}=6) .{ }^{\#}<<0.05,{ }^{\# \#} \mathrm{P}<0.01$ vs. blank control; ${ }^{*} \mathrm{P}<0.05$, ${ }^{* * *} \mathrm{P}<0.01$ vs. the model group at the same day; ${ }^{\&} \mathrm{P}<0.05$, ${ }^{\&}{ }^{\&} \mathrm{P}<0.01$, vs. day 9 in the Endostar group. ${ }^{\$} \mathrm{P}<0.05,{ }^{\$ \$} \mathrm{P}<0.01$, Endostar treatment vs. blank group. VEGF, vascular endothelial growth factor; CD31, cluster of differentiation 31; HIF-1 $\alpha$, hypoxia-inducible factor-1 $\alpha$; MMP, matrix metalloproteinase.

the optimal normalization window, the effects of Endostar on angiogenesis-associated protein expression in liver tissues were investigated during the different treatment times, including on days 1, 3, 6,9 and 12. Compared with the blank mice, the expression levels of VEGF, CD31, HIF-1 $\alpha$, MMP-2 and MMP-9 protein in the model group were increased significantly, followed by a gradual increase in protein expression levels with increasing time periods. Notably, expression of these proteins decreased significantly in the Endostar treatment group $(\mathrm{P}<0.05$; Fig. 2A).

In the Endostar-treated group, a significant decrease in VEGF was observed at a later day compared with the earlier day (day 6 compared with day 3, and day 9 compared with day 6; $\mathrm{P}<0.05)$. However, the level of VEGF was reversed to increase on day 12 (Fig. 2B). The level of CD31, an indicator of intra-tumoral microvessel density (MVD), was downregulated 
A

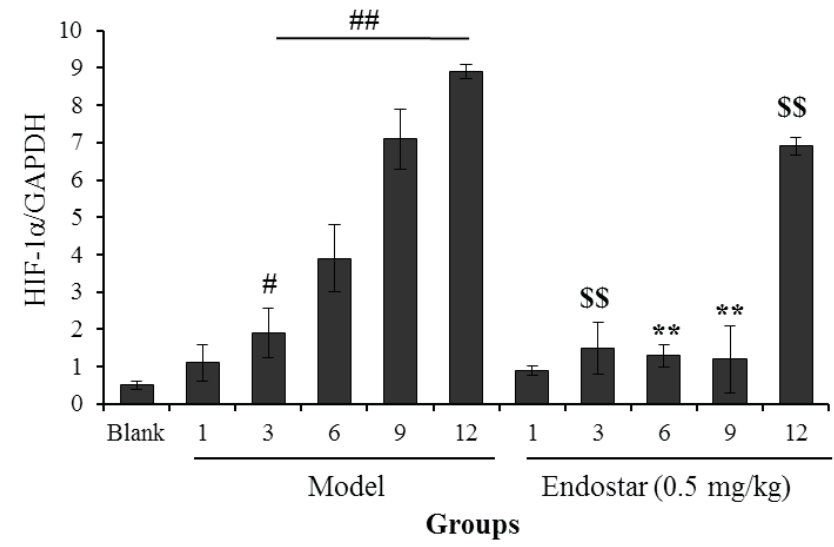

B

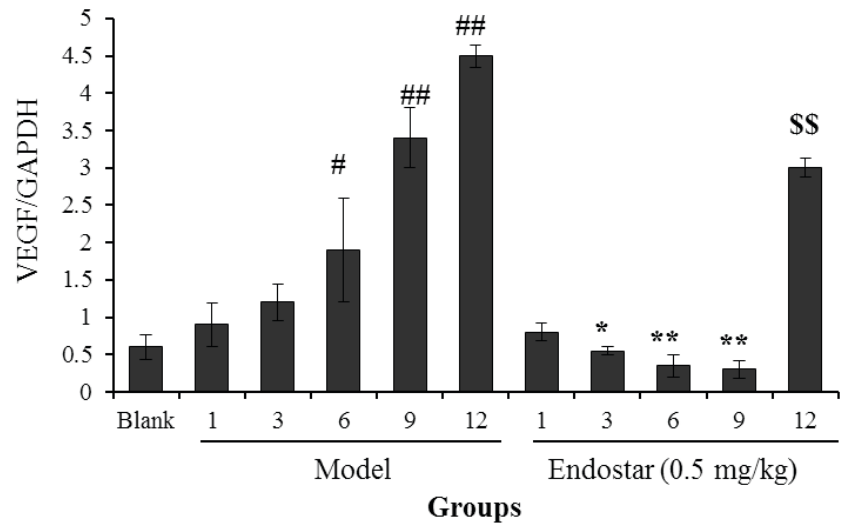

Figure 3. Effects of Endostar on the mRNA levels of (A) HIF-1 $\alpha$ and (B) VEGF in liver tissue of hepatoma 22-bearing C57BL/6 mice. All experiments were performed at least three times. Results are presented as the mean \pm standard deviation $(\mathrm{n}=6)$. ${ }^{\#} \mathrm{P}<0.05,{ }^{\# \prime} \mathrm{P}<0.01$, model vs. blank control. ${ }^{*} \mathrm{P}<0.05$, ${ }^{* *} \mathrm{P}<0.01$, Endostar treatment vs. the model group at the same day. ${ }^{\$} \mathrm{P}<0.01$, Endostar treatment vs. blank group. HIF-1 $\alpha$, hypoxia-inducible factor-1 $\alpha$; VEGF, vascular endothelial growth factor.

significantly by Endostar treatment from days 3 to 9, compared with previous days ( $\mathrm{P}<0.05$; Fig. $2 \mathrm{C}$ ), whereas HIF-1 $\alpha$, MMP-2 and MMP-9 were downregulated significantly on day 9 $(\mathrm{P}<0.05$; Fig. 2D-F). Of note, the expression levels of angiogenesis-associated proteins, including VEGF, CD31, MMP-2 and MMP-9, in Endostar-treated group were significantly decreased compared with that in the model group $(\mathrm{P}<0.05)$, but no significant difference was observed when compared with the blank control. These results indicated that days 3 to 9 may be the optimal normalization window for Endostar treatment.

Effects of Endostar on the mRNA levels of HIF-1 $\alpha$ and $V E G F$ in liver tissue of HCC mice. In order to confirm the aforementioned results, RT-PCR was used to determine the mRNA levels of HIF-1 $\alpha$ and VEGF in tumor-bearing liver tissues. As presented in Fig. 3A, the mRNA level of HIF-1 $\alpha$ was increased significantly on the third day in the model group when compared with the blank control group $(\mathrm{P}<0.05)$. Following treatment with Endostar, the HIF-1 $\alpha$ mRNA level was decreased significantly when compared with the model group $(\mathrm{P}<0.05)$. The levels of VEGF mRNA also exhibited a similar trend (Fig. 3B). For HIF-1 $\alpha$ and VEGF mRNA levels in the Endostar-treated group, the level of HIF-1 $\alpha$ mRNA was decreased significantly on days 3,6 and $9(\mathrm{P}<0.01)$, whereas VEGF mRNA levels were decreased on day $9(\mathrm{P}<0.01)$. These results also suggest that days 3 to 9 may be the optimal vascular normalization window for Endostar.

Effects of Endostar on TNF- $\alpha$ in liver tissue of HCC mice. Immune factors are involved in the angiogenesis of HCC and contribute to the vascular normalization (27). TNF- $\alpha$, an inflammatory cytokine, has been shown to be associated with HCC (28). The hepatic TNF- $\alpha$ level increased progressively in the model group with increasing time, and increased from low levels of $0.95 \pm 0.12 \mathrm{pg} / \mathrm{mg}$ at day 1 to $3.51 \pm 0.91,5.36 \pm 0.74$, $7.18 \pm 0.71$ and $7.31 \pm 0.13 \mathrm{pg} / \mathrm{mg}$ at days $3,6,9$ and 12 , respectively (Table I). The TNF- $\alpha$ level was decreased significantly following administration at days 3 to $9(\mathrm{P}<0.05)$.
Effects of Endostar on IFN- $\gamma, I L-17$ and CD86 in liver tissue of HCC mice. In order to explore the effect of Endostar on angiogenesis in HCC mice, the levels of immune factors IFN- $\gamma$, IL-17 and CD86 were evaluated in the liver tissues on the sixth day. The levels of IFN- $\gamma$ and CD86 in the model group were identified to be significantly lower compared with the blank control group $(\mathrm{P}<0.01)$. Results of immunohistochemistry (Fig. 4A), ELISA (Fig. 4B) or western blotting (Fig. 4C and D) demonstrated that Endostar was able to enhance the decreased IFN- $\gamma$ level $(\mathrm{P}<0.01)$. Results of Fig. 5 showed that Endostar was able to enhance the decreased CD86 level $(\mathrm{P}<0.01)$. For IL-17, a significant decrease was observed in model group, whereas this decrease was enhanced by the treatment of Endostar (Fig. 6). These results indicated that the immunomodulatory factors were involved in the angiogenesis of HCC mice and Endostar was able to promote vascular normalization by regulating these factors.

\section{Discussion}

$\mathrm{HCC}$ is a primary cancer that leads to mortality, and the number of cases is increasing from year to year (29). The development of HCC is closely associated with angiogenesis (30). Endostar, a recombinant human endostatin for inhibiting angiogenesis, was developed originally for the treatment of lung cancer and was also used for HCC treatment (31). This mechanism can be achieved by inhibiting endothelial cell migration to inhibit tumor angiogenesis and to block the nutrient supply of tumor cells (32). Therefore, normalization of blood vessels of HCC serves an important role in the target of Endostar to tumor cells. In the present study, experimental evidence for the vascular normalization window of Endostar was provided and the role of immune response in anti-angiogenesis of Endostar was also examined.

In the present study, H22-bearing C57BL/6 mice were used to establish a HCC model. In a previous study, a rabbit VX2 model was used to evaluate the anti-angiogenic effects of Endostar (33). H22-bearing C57BL/6 mice were used for two reasons: i) mouse models are more convenient and economical; 

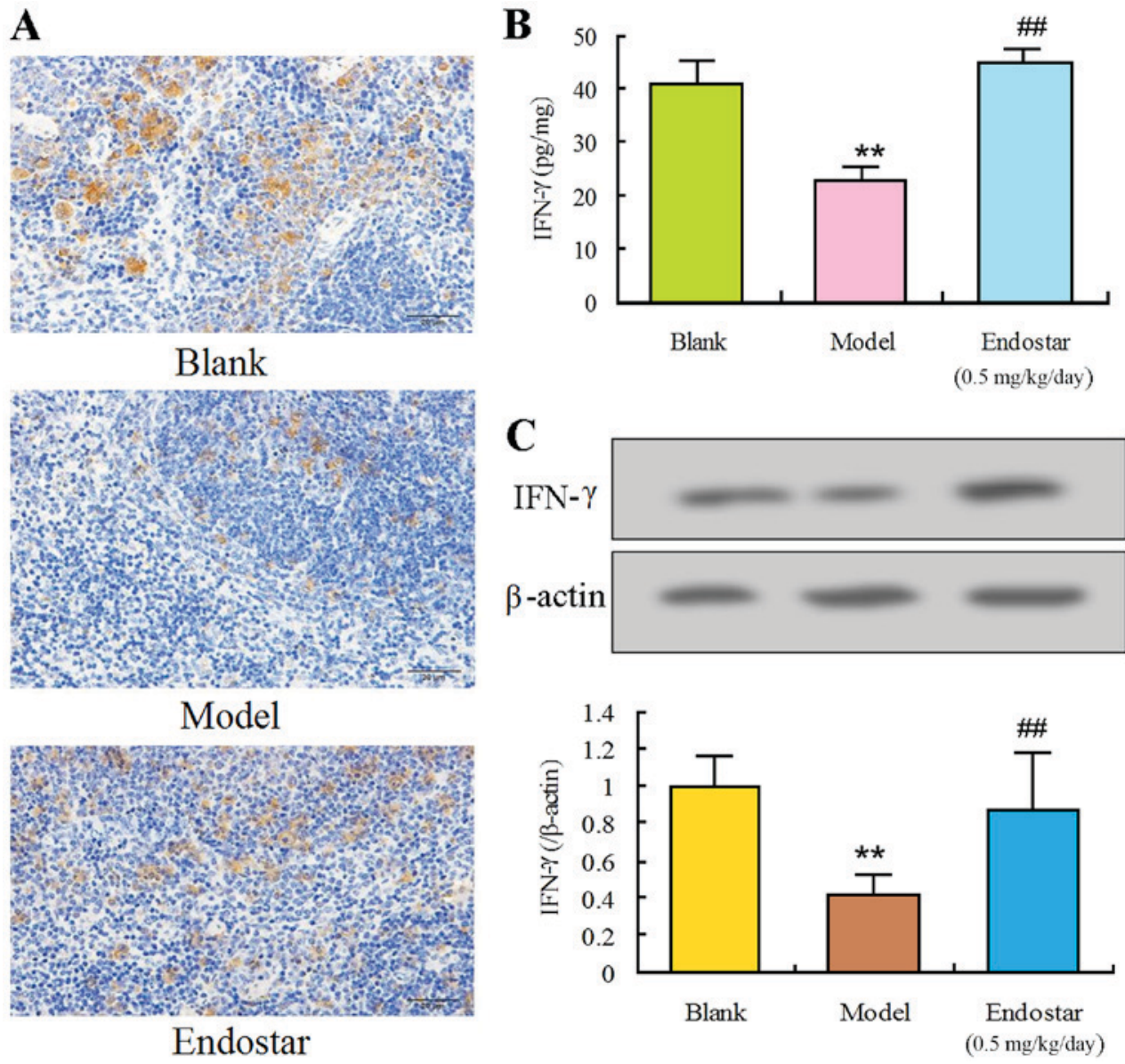

Figure 4. Regulation of IFN- $\gamma$ by Endostar in liver tissue of hepatocellular carcinoma mice. (A) Immunohistochemistry for IFN- $\gamma$. (B) ELISA for IFN- $\gamma$. (C) Western blotting for IFN $-\gamma$. Results are presented as the mean \pm standard deviation $(n=6)$. ${ }^{* *} \mathrm{P}<0.01$, model vs. blank control; ${ }^{\# \#} \mathrm{P}<0.01$, Endostar treatment vs. the model group. IFN- $\gamma$, interferon- $\gamma$.
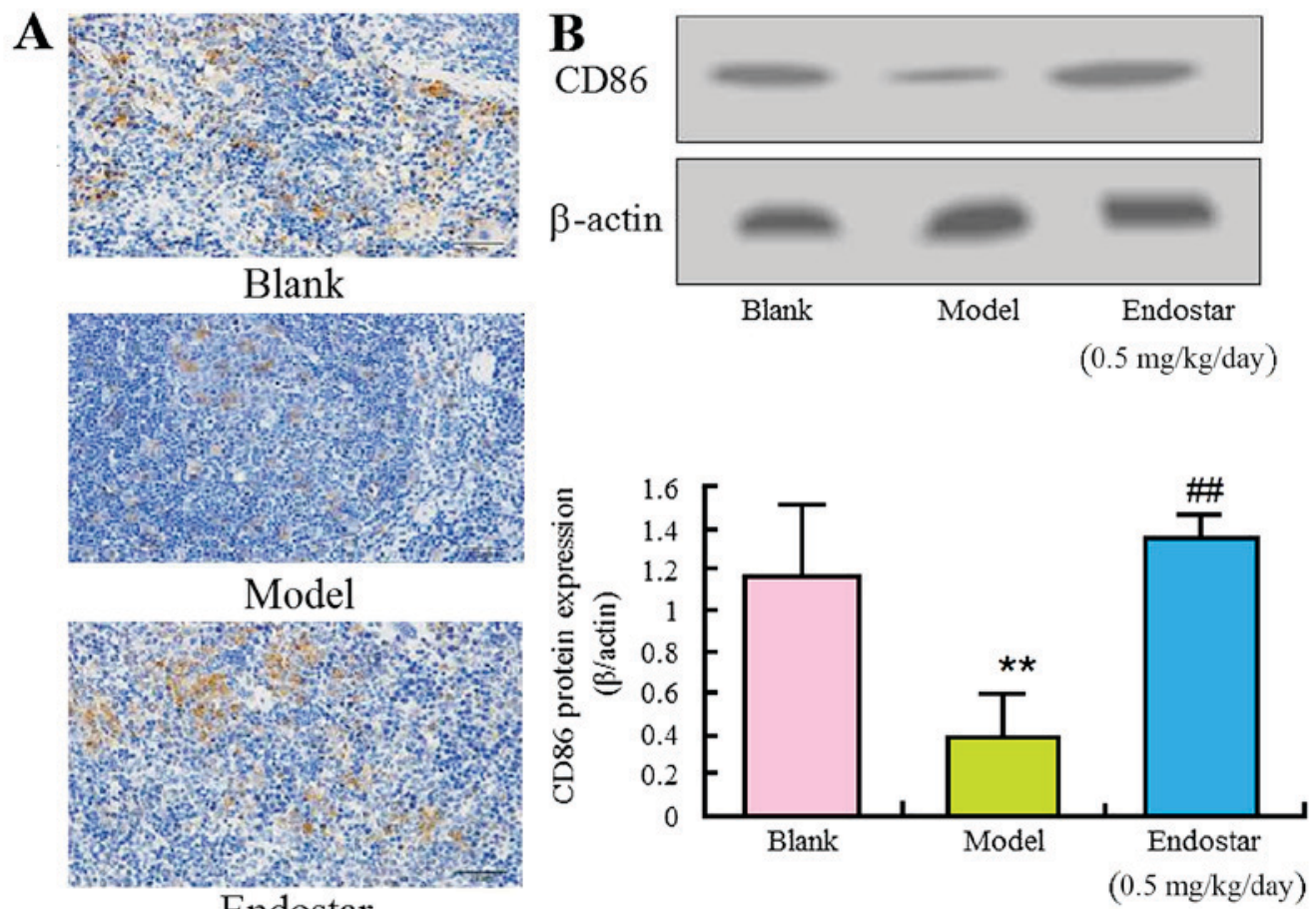

Figure 5. Regulation of CD86 by Endostar in liver tissue of HCC mice. (A) Immunohistochemistry for CD86; (B) Western blotting for CD86. Results are presented as the mean \pm standard deviation $(\mathrm{n}=6) .{ }^{* *} \mathrm{P}<0.01$, model vs. blank control; ${ }^{\# \#} \mathrm{P}<0.01$, Endostar treatment vs. the model group. CD86, cluster of differentiation 86 . 


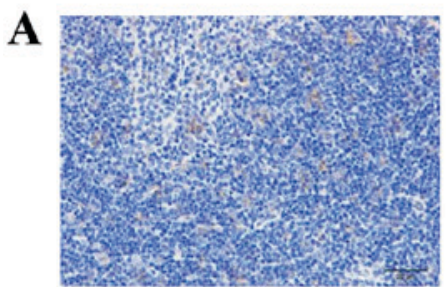

Blank

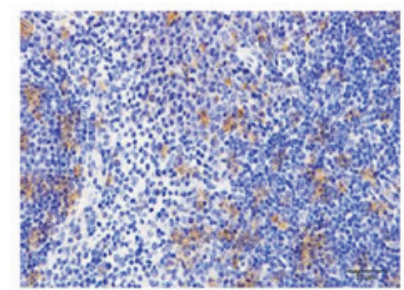

Model

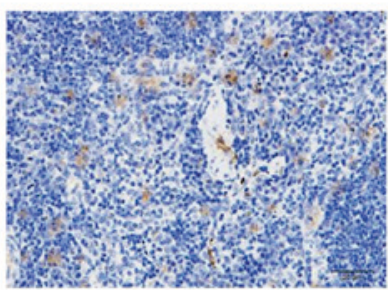

Endostar
B

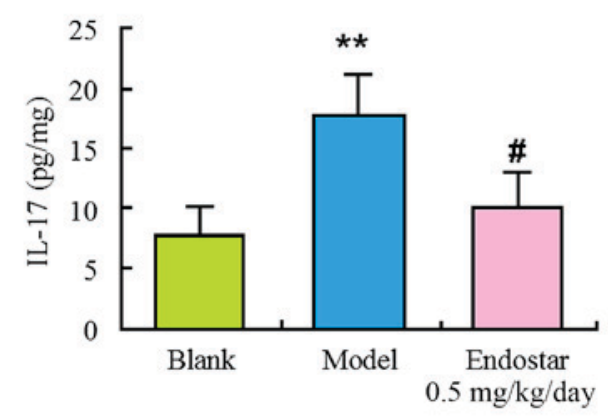

C
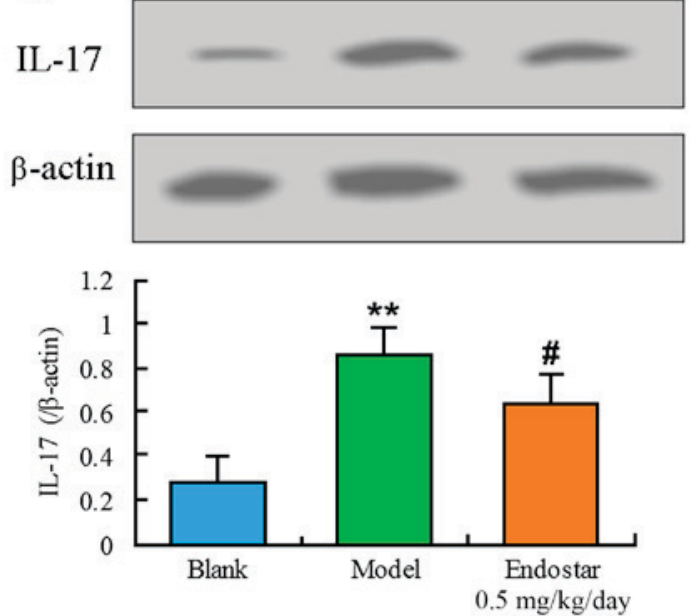

Figure 6. Regulation of IL-17 by Endostar in liver tissue of hepatocellular carcinoma mice. (A) Immunohistochemistry for IL-17; (B) ELISA for IL-17; (C) Western blotting for IL-17. Results are presented as the mean \pm standard deviation $(\mathrm{n}=6)$. ${ }^{* *} \mathrm{P}<0.01$, model vs. blank control; ${ }^{\#} \mathrm{P}<0.05$, Endostar treatment vs. the model group. IL-17, interleukin-17.

and ii) compared with that of rabbits, the mouse genome is more similar to that of humans. The established mice model has certain advantages for the anti-angiogenic effects of Endostar.

AFP is produced by the majority of hepatocellular carcinomas and is directly associated with the severity of the disease (34). Owing to the increased expression of AFP in pathological liver tissue, it remains the only serum marker for the diagnosis of HCC (35). The level of AFP in the serum is a marker for assessing the response to therapy and a marker of disease progression and survival of HCC (36). It has been identified that lysophosphatidic acid (LPA) is a marker of HCC (37), and LPA was known to be associated with tissue fibrosis (38) in patients with HCC. LPA has previously been linked to cellular signaling molecules (cAMP) and pro-inflammatory cytokines (TNF- $\alpha)(39,40)$. In the present study, serum AFP and TNF- $\alpha$ were typically increased, whereas cAMP levels were markedly decreased in mice with HCC when compared with blank controls. Following treatment with Endostar, serum AFP levels and TNF- $\alpha$ were decreased significantly compared with mice in the model group from day 3 to 9. Endostar treatment resulted in significantly increasing cAMP levels compared with the model group at the same time until day 12 . Therefore, it is hypothesized that Endostar may improve levels of AFP, TNF- $\alpha$ and cAMP in H22-bearing mice following administration at days 3 to 9 , meaning that the effective time continued for 6 days.

Excessive proliferation of tumor cells resulted in tumor tissue hypoxia, leading to angiogenesis, increased drug resistance, enhanced metastatic ability and other adaptive responses (41). HIF-1 $\alpha$ serves an important role in the hypoxic condition of internal tumors (42). Increased expression of HIF-1 $\alpha$ is associated with oxygen content sensing and signaling in internal tumors (43). HIF- $1 \alpha$ can promote the secretion of downstream cytokines, including extracellular matrix metalloproteinase inducer (EMMPRIN) (44), VEGF and MMP-9 (45). The results of the present study demonstrated increased expression of HIF-1 $\alpha$ in liver tissues of model mice, whereas low expression was observed in the blank control and Endostar-treated groups. These results indicated that the aerobic condition in Endostar-treated groups was consistent with that in the blank control group, namely that angiogenesis of Endostar may be adjusted to vascular normalization to provide sufficient oxygen.

Certain cytokines are able to cause endothelial cell migration, adhesion and migration into the tumor tissue, to eventually achieve tumor angiogenesis (46). VEGF is the most important tumor angiogenesis-stimulating factor (47). VEGF protects endothelial cells against apoptosis, enhances vascular permeability and increases expression of MMPs (48). MMPs are a group of zinc-dependent proteolytic enzymes that degrade extracellular matrix components, with the exception of polysaccharides. MMPs increase the permeability of capillaries, thus promoting recycling of liquid, endothelial cells and tumor cells leaking from the blood vessels (49). MMPs perform an important role in angiogenesis by directly contributing to the promotion of capillary growth in the sprouting model (50). 
MMPs can be regulated by EMMPRIN and tissue inhibitor of metalloproteinases (51). Levels of angiogenic cytokines were significantly increased by MMPs in tumor tissue, and the level of anti-angiogenic factors was decreased, resulting in abnormal proliferation of tumor blood vessels, including increased microvascular density, tortuous shape, expansion and increased bifurcations (52). In the present study, Endostar was identified to normalize the structure and function of blood vessels within the tumor microenvironment temporarily by upregulating the expression of angiogenesis-promoting factors. The results suggested that the expression levels of angiogenic factors VEGF, MMP-2, MMP-9 and HIF-1 $\alpha$ were decreased following Endostar treatment for 3 days. A normalization of vasculature was achieved with the decrease in MVD, the increase in collagen coverage and the decrease in leakage of blood vessel walls. However, this process lasted only 6 days. The tumor blood vessels achieved a short-term normalization, with a window period from day 3 to 9 .

The immune response has been demonstrated to be involved in tumor anti-angiogenesis (53). Immune factors are involved in tumor development, angiogenesis and immune response (54). A previous study demonstrated that CTLA4-Ig/CD86 interaction on IFN- $\gamma$ and IL-17 activated human umbilical vein endothelial cell modulation in the expression of VEGFR-2, relevant for inflammatory and angiogenic processes (14). The blockade of CD86 ligands from binding to CD28 by the modulation of CTLA4-Ig on T cell costimulatory signals (55). The stimulated Th1/Th2 induced the secretion of cytokine IFN- $\gamma$ by switching the Th1 to Th2 response (56). Regulatory $\mathrm{T}$ cells are able to differentiate into Th17 cells to produce IL-17 (57). The results of the present study indicated that Endostar treatment was able to increase IFN- $\gamma$ and CD86 levels and decrease the level of IL-17 in HCC mice. VEGF may serve an important role in tumor development, progression and immunosuppression associated with CD86 (58). Therefore, it was hypothesized that vascular normalization of Endostar may be associated with the suppression on Th17 response and regulation on Th1/Th2 imbalance.

To the best of our knowledge, the present study is the first to confirm that the vascular normalization window of Endostar for anti-angiogenesis is from day 3 to 9 in H22-bearing HCC mice. Its regulation of antitumor immunity was involved in the anti-angiogenesis activity. These results provide experimental evidence for the vascular normalization window applied in the combination of Endostar with other chemotherapy.

\section{Acknowledgements}

The authors gratefully acknowledge the financial support of the National Natural Science of China (grant no. 81202906), Natural Science Foundation of Jiangsu (grant no. BK2012491) and National Natural Science Foundation of China (grant no. 81130070$)$.

\section{References}

1. Llovet JM, Burroughs A and Bruix J: Hepatocellular carcinoma. Lancet 362: 1907-1917, 2003.

2. Gish RG and Baron A: Hepatocellular carcinoma (HCC): Current and evolving therapies. IDrugs 11: 198-203, 2008.

3. Bruix J, Sala M and Llovet JM: Chemoembolization for hepatocellular carcinoma. Gastroenterology 127: 179-188, 2004.
4. Gacche RN: Compensatory angiogenesis and tumor refractoriness. Oncogenesis 4: e153, 2015.

5. Folkman J: Role of angiogenesis in tumor growth and metastasis. Semin Onco 129 (6 Suppl 16): S15-S18, 2002.

6. Zhang $\mathrm{C}$, Li K and Wang J: The effect of rh-endostatin on micrangium and angiogenic factors in tumor and myocardium tissue. Chin German J Clin Oncol 11: 43-48, 2012.

7. Yan JC, Ding S, Liang Y, Liu PJ, Ren GQ, Zhu J, Ma GS, et al: Effect of CD_(40)-CD_(40) ligand interaction on proliferation and migration in cultured human umbilical vein endothelial cells. China J Modern Med: 2496-2499, 2007 (In Chinese).

8. Murphy JF, Lennon F, Steele C, Kelleher D, Fitzgerald D and Long AC: Engagement of CD44 modulates cyclooxygenase induction, VEGF generation, and cell proliferation in human vascular endothelial cells. FASEB J 19: 446-448, 2005.

9. Ao JY, Chai ZT, Zhang YY,Zhu XD, Kong LQ, Zhang N, Ye BG Cai H, Gao DM and Sun HC: Robol promotes angiogenesis in hepatocellular carcinoma through the Rho family of guanosine triphosphatases' signaling pathway. Tumour Biol 36: 8413-8424, 2015.

10. Ling Y, Yang Y, Lu N, You QD, Wang S, Gao Y, Chen Y and Guo QL: Endostar, a novel recombinant human endostatin, exerts antiangiogenic effect via blocking VEGF-induced tyrosine phosphorylation of KDR/Flk-1 of endothelial cells. Biochem Biophys Res Commun 361: 79-84, 2007.

11. Wang S, Lu XA, Liu P, Fu Y, Jia L, Zhan S and Luo Y: Endostatin has ATPase activity, which mediates its antiangiogenic and antitumor activities. Mol Cancer Ther 14: 1192-1201, 2015.

12. Liu F, Tan G, Li J, Dong X, Krissansen GW and Sun X: Gene transfer of endostatin enhances the efficacy of doxorubicin to suppress human hepatocellular carcinomas in mice. Cancer Sci 98: 1381-1387, 2007

13. Lin K, Ye P, Liu J, He F and $\mathrm{Xu} \mathrm{W}$ : Endostar inhibits hypoxia-induced cell proliferation and migration via the hypoxia-inducible factor- $1 \alpha /$ vascular endothelial growth factor pathway in vitro. Mol Med Rep 11: 3780-3785, 2015.

14. Li N, Zheng D, Wei X, Jin Z, Zhang C and Li K: Effects of recombinant human endostatin and its synergy with cisplatin on circulating endothelial cells and tumor vascular normalization in A549 xenograft murine model. J Cancer Res Clin Oncol 138: 1131-1144, 2012.

15. Huang $\mathrm{G}$ and Chen L: Recombinant human endostatin improves anti-tumor efficacy of paclitaxel by normalizing tumor vasculature in Lewis lung carcinoma. J Cancer Res Clin Oncol 136: 1201-1211, 2010.

16. Zhao W, Zhang L, Yin Z, Su W, Ren G, Zhou C, You J, Fan J and Wang X: Activated hepatic stellate cells promote hepatocellular carcinoma development in immunocompetent mice. Int $\mathrm{J}$ Cancer 129: 2651-2661, 2011.

17. Khan MA, Assiri AM and Broering DC: Complement and macrophage crosstalk during process of angiogenesis in tumor progression. J Biomed Sci 22: 58, 2015.

18. Gomes FG, Nedel F, Alves AM, Nör JE and Tarquinio SB: Tumor angiogenesis and lymphangiogenesis: Tumor/endothelial crosstalk and cellular/microenvironmental signaling mechanisms. Life Sci 92: 101-107, 2013.

19. Tassi E and Wellstein A: Tumor angiogenesis: Initiation and targeting-therapeutic targeting of an FGF-binding protein, an angiogenic switch molecule, and indicator of early stages of gastrointestinal adenocarcinomas. Cancer Res Treat 38: 189-197, 2006.

20. Cutolo M, Montagna P, Soldano S, Contini P, Paolino S Pizzorni C, Seriolo B, Sulli A and Brizzolara R: CTLA4-Ig/CD86 interactions in cultured human endothelial cells: Effects on VEGFR-2 and ICAM1 expression. Clin Exp Rheumatol 33: 250-254, 2015.

21. Fagiani E, Bill R, Pisarsky L, Ivanek R, Rüegg C and Christofori G: An immature B cell population from peripheral blood serves as surrogate marker for monitoring tumor angiogenesis and anti-angiogenic therapy in mouse models. Angiogenesis 18: 327-345, 2015.

22. Gao SR, Li LM, Xia HP, Wang GM, Xu HY and Wang AR: Clinical observation on recombinant human endostatin combined with chemotherapy for advanced gastrointestinal cancer. Asian Pac J Cancer Prev 16: 4037-4040, 2015.

23. Persad R, Liu C, Wu TT, Houlihan PS, Hamilton SR, Diehl AM and Rashid A: Overexpression of caspase-3 in hepatocellular carcinomas. Mod Pathol 17: 861-867, 2004. 
24. Livak KJ and Schmittgen TD: Analysis of relative gene expression data using real-time quantitative PCR and the 2(-Delta Delta C(T)) method. Methods 25: 402-408, 2001.

25. Liu J, Wang S, Feng L, Ma D, Fu Q, Song Y, Jia X and Ma S: Hypoglycemic and antioxidant activities of paeonol and its beneficial effect on diabetic encephalopathy in streptozotocin-induced diabetic rats. J Med Food 16: 577-586, 2013.

26. Territo PR, Maluccio M, Riley AA, McCarthy BP, Fletcher J, Tann M, Saxena R and Skill NJ: Evaluation of 11C-acetate and 18 F-FDG PET/CT in mouse multidrug resistance gene-2 deficient mouse model of hepatocellular carcinoma. BMC Med Imaging 15: 15, 2015.

27. Fujii T, Nomoto S, Koshikawa K, Yatabe Y, Teshigawara O, Mori T, Inoue S, Takeda S and Nakao A: Overexpression of pituitary tumor transforming gene 1 in $\mathrm{HCC}$ is associated with angiogenesis and poor prognosis. Hepatology 43: 1267-1275, 2006.

28. Roderburg C, Gautheron J and Luedde T: TNF-dependent signaling pathways in liver cancer: Promising targets for therapeutic strategies? Dig Dis 30: 500-507, 2012.

29. Dhanasekaran R, Limaye A and Cabrera R: Hepatocellular carcinoma: Current trends in worldwide epidemiology, risk factors, diagnosis, and therapeutics. Hepat Med 4: 19-37, 2012.

30. Zhu JY, Sun QK, Wang W and Jia WD: High-level expression of HOXB13 is closely associated with tumor angiogenesis and poor prognosis of hepatocellular carcinoma. Int J Clin Exp Pathol 7: 2925-2933, 2014

31. Ye Q, Qin S, Liu Y, Feng J, Wu Q, Qu W and Yin X: Inhibitory effect of Endostar on specific angiogenesis induced by human hepatocellular carcinoma. Gastroenterol Res Pract 2015: 957574 2015.

32. Buachan P, Chularojmontri L and Wattanapitayakul SK: Selected activities of Citrus maxima Merr. Fruits on human endothelial cells: Enhancing cell migration and delaying cellular aging. Nutrients 6: 1618-1634, 2014

33. Feng G, Lei Z, Wang D, Xu N, Wei Q, Li D and Liu J: The evaluation of anti-angiogenic effects of Endostar on rabbit VX2 portal vein tumor thrombus using perfusion MSCT. Cancer Imaging 14 17, 2014.

34. Bialecki ES and Di Bisceglie AM: Diagnosis of hepatocellular carcinoma. HPB (Oxford) 7: 26-34, 2005.

35. Bayati N, Silverman AL and Gordon SC: Serum alpha-fetoprotein levels and liver histology in patients with chronic hepatitis $\mathrm{C}$ Am J Gastroenterol 93: 2452-2456, 1998.

36. Riaz A, Ryu RK, Kulik LM, Mulcahy MF, Lewandowski RJ, Minocha J, Ibrahim SM, Sato KT, Baker T, Miller FH, et al: Alpha-fetoprotein response after locoregional therapy for hepatocellular carcinoma: Oncologic marker of radiologic response, progression, and survival. J Clin Oncol 27: 5734-5742, 2009.

37. Skill NJ, Jianmin W, Yan X, Zhao Z, Tector AJ and Maluccio MA: Lysophospholipid variants in hepatocellular carcinoma. J Surg Res 182: 241-249, 2013

38. Rancoule C, Pradère JP, Gonzalez J, Klein J, Valet P, Bascands JL, Schanstra JP and Saulnier-Blache JS: Lysophosphatidic acid-1-receptor targeting agents for fibrosis. Expert Opin Investig Drugs 20: 657-667, 2011.

39. Jongsma M, Matas-Rico E, Rzadkowski A, Jalink $K$ and Moolenaar WH: LPA Is a chemorepellent for B16 melanoma cells: Action through the cAMP-Elevating LPA5 receptor. PLoS One 6: e29260, 2011.

40. Zhao C, Sardella A, Chun J, Poubelle PE, Fernandes MJ and Bourgoin SG: TNF-alpha promotes LPA1-and LPA3-mediated recruitment of leukocytes in vivo through CXCR2 ligand chemokines. J Lipid Res 52: 1307-1318, 2011.

41. Betof AS, Lascola CD, Weitzel D, Landon C, Scarbrough PM, Devi GR, Palmer G, Jones LW and Dewhirst MW: Modulation of murine breast tumor vascularity, hypoxia and chemotherapeutic response by exercise. J Natl Cancer Inst 107: pii: djv040, 2015.

42. Zhang J, Liu Q, Hu X, Fang Z, Huang F, Tang L and Zhou S: Apelin/APJ signaling promotes hypoxia-induced proliferation of endothelial progenitor cells via phosphoinositide-3 kinase/Akt signaling. Mol Med Rep 12: 3829-3834, 2015.

43. Wang J and Hao J: Role of HIF-1 $\alpha$ in hypoxic microenvironment of tumor and the targeted therapy. Chin J Clin Oncol: 1072-1075, 2013.

44. Monteiro LS, Delgado ML, Ricardo S, Garcez F, do Amaral B, Pacheco JJ, Lopes C and Bousbaa H: EMMPRIN expression in oral squamous cell carcinomas: Correlation with tumor proliferation and patient survival. Biomed Res Int 2014: 905680, 2014.
45. Kowshik J, Mishra R, Sophia J, Rautray S, Anbarasu K, Reddy GD, Dixit M, Mahalingam S and Nagini S: Nimbolide upregulates RECK by targeting miR-21 and HIF-1 $\alpha$ in cell lines and in a hamster oral carcinogenesis model. Sci Rep 7: 2045, 2017.

46. Huang H, Song Y, Wu Y, Guo N, Ma Y and Qian L: Erbin loss promotes cancer cell proliferation through feedback activation of Akt-Skp2-p27 signaling. Biochem Biophys Res Commun 463: 370-376, 2015

47. Kazemi-Lomedasht F, Behdani M, Pooshang Bagheri K, Habibi Anbouhi M, Abolhassani M, Khanahmad H, Shahbazzadeh D and Mirzahoseini H: Expression and purification of functional human vascular endothelial growth factor-A121; the most important angiogenesis factor. Adv Pharm Bull 4: 323-328, 2014.

48. Huang TH, Chiu YH, Chan YL, Chiu YH, Wang H, Huang KC, $\mathrm{Li} \mathrm{TL}$, Hsu KH and $\mathrm{Wu} \mathrm{CJ}$ : Prophylactic administration of fucoidan represses cancer metastasis by inhibiting vascular endothelial growth factor (VEGF) and matrix metalloproteinases (MMPs) in Lewis tumor-bearing mice. Mar Drugs 13: 1882-1900, 2015.

49. Lopez-Avila V and Spencer J: Methods for detection of matrix metalloproteinases as biomarkers in cardiovascular disease. Clin Med Insights Cardiol 2: 75-87, 2008.

50. Alexius-Lindgren M, Andersson E, Lindstedt I and Engström W: The RECK gene and biological malignancy-its significance in angiogenesis and inhibition of matrix metalloproteinases. Anticancer Res 34: 3867-3873, 2014.

51. Emingil G, Tervahartiala T, Mãntylã P, Määttä M, Sorsa T and Atilla G: Gingival crevicular fluid matrix metalloproteinase (MMP)-7, extracellular MMP inducer, and tissue inhibitor of MMP-1 levels in periodontal disease. J Periodontol 77: 2040-2050, 2006.

52. Monteiro-Amado F, Castro-Silva II, Lima CJ, Soares FA, Kowalski LP and Granjeiro JM: Immunohistochemical evaluation of MMP-2, MMP-9 and CD31/microvascular density in squamous cell carcinomas of the floor of the mouth. Braz Dent J 24: 3-9, 2013

53. Griffioen AW: Anti-angiogenesis: Making the tumor vulnerable to the immune system. Cancer Immunol Immunother 57: $1553-1558,2008$.

54. Sabnani MK, Rajan R, Rowland B, Mavinkurve V, Wood LM, Gabizon AA and La-Beck NM: Liposome promotion of tumor growth is associated with angiogenesis and inhibition of antitumor immune responses. Nanomedicine 11: 259-262, 2015.

55. Mu X, Sang Y, Fang C, Shao B, Yang L, Yao K, Zhao X, Gou J, Wei Y, Yi T, et al: Immunotherapy of tumors with human telomerase reverse transcriptase immortalized human umbilical vein endothelial cells. Int J Oncol 47: 1901-1911, 2015.

56. Zhu J, Wang Y, Yang F, Sang L, Zhai J, Li S, Li Y, Wang D, Lu C and Sun X: IL-33 alleviates DSS-induced chronic colitis in C57BL/6 mice colon lamina propria by suppressing Th17 cell response as well as Th1 cell response. Int Immunopharmacol 29: 846-853, 2015

57. Gagliani N, Amezcua Vesely MC, Iseppon A, Brockmann L, Xu H, Palm NW, de Zoete MR, Licona-Limón P, Paiva RS, Ching T, et al: Th17 cells transdifferentiate into regulatory T cells during resolution of inflammation. Nature 523: 221-225, 2015.

58. Wang H, Zhang L, Zhang S and Li Y: Inhibition of vascular endothelial growth factor by small interfering RNA upregulates differentiation, maturation and function of dendritic cells. Exp Ther Med 9: 120-124, 2015

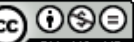

This work is licensed under a Creative Commons Attribution-NonCommercial-NoDerivatives 4.0 International (CC BY-NC-ND 4.0) License. 